\title{
Análise Comparativa dos Clusters de Empresas de Tecnologia da Informação de São Paulo, Campinas e Recife
}

\author{
Veneziano Araujo \\ Universidade Federal de São Paulo - São Paulo - SP - Brasil \\ Ana Laura Costa Lopes \\ Universidade Federal de São Paulo - São Paulo - SP - Brasil
}

\section{Resumo}

Este trabalho tem por objetivo aprofundar nos estudo dos clusters de empresas do setor de Tecnologia da Informação (TI) avaliando comparativamente as regiões de São Paulo, Campinas e Recife. A comparação é feita pela revisão de estudos prévios e pela análise de dados sobre empresas e universidades locais. Ela se centra nos elementos constitutivos do cluster (empresas, universidade e governo) e nos seus benefícios (fornecedores especializados, trabalhadores qualificados e fluxos de conhecimento). A comparação permite destacar elementos comuns e particularidades. Entre as similaridades destacam-se a preponderância de pequenas e médias empresas do segmento de software, a presença de universidades de ponta e a dependência do financiamento público. Já entre as particularidades, evidencia-se a importância da indústria de hardware em Campinas, a maior coesão de Recife e o aprendizado pela relação cliente-produtor em São Paulo.

Palavras-chave: Economia Regional e Urbana. clusters de empresas. Tecnologia da Informação.

\section{Comparative Analysis of Clusters of Information Technology Firms in São Paulo, Campinas and Recife}

\begin{abstract}
The aim of this article is to evaluate and compare clusters of Information Technology (IT) sector firms located in São Paulo, Campinas and Recife regions. This comparison is based in previous studies on these clusters and use databases on firms and university. It focuses on structural elements of the cluster (firms, university and government) and on the benefits of agglomeration (specialized suppliers and skilled workers and knowledge flows). The comparison highlights common elements and peculiarities of these clusters. Among the similarities are the preponderance of small and medium-sized companies in the software segment, the presence of leading universities and the dependence on public financing. In the field of particularities, it is
\end{abstract}


evident the importance of the hardware industry in Campinas, the greater cohesion of Recife and the learning by customer-producer relationship in São Paulo.

Keywords: industrial clusters. Information Technology. knowledge and innovation.

\title{
Análisis Comparativo de Clusters de Empresas de Tecnologías de la Información en São Paulo, Campinas y Recife
}

\begin{abstract}
Resumen
El objetivo de este artículo es evaluar y comparar clusters de empresas del sector de Tecnologías de la Información ( $\mathrm{TI}$ ) ubicadas en las regiones de São Paulo, Campinas y Recife. Esta comparación se basa en estudios anteriores sobre estos conglomerados y utiliza bases de datos sobre empresas y universidades. Se centra en los elementos estructurales del cluster (empresas, universidad y gobierno) y en los beneficios de la aglomeración (proveedores especializados y trabajadores calificados y flujos de conocimiento). La comparación destaca los elementos comunes y peculiaridades de estos grupos. Entre las similitudes están la preponderancia de las pequeñas y medianas empresas en el segmento de software, la presencia de universidades líderes y la dependencia de la financiación pública. En el campo de las particularidades, es evidente la importancia de la industria del hardware en Campinas, la mayor cohesión de Recife y la relación aprendizaje-cliente-productor en São Paulo.
\end{abstract}

Palabras claves: clusters industriales. Tecnología de la Información. Conocimiento e innovación.

\section{INTRODUÇÃO}

A concentração de empresas de um mesmo setor em uma localidade, conhecida como cluster, se tornou importante objeto de pesquisa devido ao seu dinamismo econômico e a casos emblemáticos de regiões bem sucedidas. Um cluster não sedia apenas empresas, mas também uma variedade de agentes interligados como fornecedores, universidades e agentes governamentais. E essa concentração tende a aumentar a inovação e produtividade sustentada por um amplo contingente de trabalhadores qualificados, fornecedores especializados e pelo fluxo de conhecimentos e informações relacionadas ao setor.

O setor de Tecnologia da Informação ( $\mathrm{TI}$ ) possui casos emblemáticos de localidades que se configuram como cluster tecnológicos de renome mundial, onde estão sediadas empresas líderes nos mais variados segmentos desse setor. Esses clusters ocorrem em países desenvolvidos (como o Vale do Silício, nos Estados Unidos) ou em desenvolvimento (como Bangalore, na Índia). Para os países em desenvolvimento como o Brasil, a formação de clusters tecnológicos possui relevância adicional por ajudar a superar a deficiência histórica em setores econômicos mais dinâmicos, como as indústrias e serviços de alta tecnologia. Além disso, é preciso ter em conta que o setor de TI não é importante para uma Economia apenas pelo alto valor agregado de seus produtos e serviços, mas porque há grande pervasividade desse setor que fornece serviços e produtos que aumentam a produtividade dos demais setores.

Nesse contexto, o presente trabalho tem por objetivo analisar comparativamente três clusters tecnológicos expressivos no cenário nacional (São Paulo, Campinas e Recife) com foco na estrutura dos agentes locais (empresas, universidades e governo) e os de sua 
cadeia (fornecedores, profissionais e fluxo de ideias), além da infraestrutura de apoio e financiamento. Essa análise se embasa em trabalhos prévios sobre esses aglomerados e em dados secundários relacionados às empresas, ao emprego e à universidade dessas localidades.

A opção dessa estrutura analítica se embasa nos conceitos relacionados aos Arranjos Produtivos Locais (APLs) (CASSIOLATO; LASTRES, 2001; SUZIGAN et al., 2004) e no paradigma da Hélice Tripla (ETZKOWITZ; LEYDESDORFF, 2000) que destaca a importância de empresas, universidade e governo para o desenvolvimento regional. A opção por uma análise comparada se justifica porque, ainda que o Brasil esteja composto por diversos clusters de tecnologia (BRITTO; STALLIVIERI, 2010), a maioria dos trabalhos sobre clusters tecnológicos nacionais são análises individuais, sendo raros os estudos comparativos. As análises comparativas permitem destacar elementos comuns e particularidades dos clusters que auxiliam na formulação de políticas locais ou para o setor de TI.

Entre as similaridades encontradas nos três casos analisados destacam-se a preponderância das pequenas e médias empresas do segmento de software, a presença de universidades de ponta e a dependência do financiamento público. Já no campo das particularidades, os resultados evidenciam a importância da indústria de hardware em Campinas, a maior coesão de Recife e o aprendizado pela relação cliente-produtor em São Paulo.

Este artigo está estruturado em seis seções. A primeira revisa a literatura sobre os determinantes da formação e do desempenho dos clusters de empresas. A segunda seção apresenta um breve panorama sobre o setor de TI no Brasil e sua distribuição regional. A terceira seção apresenta as opções metodológicas utilizadas. A quarta apresenta brevemente os casos de São Paulo, Caminas e Recife a partir de estudos prévios. A quinta seção expõe a análise comparativa a partir das dimensões estudadas e os principais achados são resumidos em um quadro comparativo. Por fim, na última seção, são tecidas as conclusões e considerações finais.

\section{Revisão da Literatura sobre Clusters de Empresas}

Os benefícios da concentração geográfica de empresas de um mesmo setor econômico foram amplamente debatidos na literatura. Mesmo partindo de diferentes enfoques teóricos, esses trabalhos possuem de maneira geral origem comum no estudo seminal de Marshall sobre os distritos industriais ingleses do séc. XIX. No Brasil, o tema possui algumas contribuições destacadas como as de Cassiolato e Lastres (2001), Suzigan (2001), Suzigan et al. (2004) e Fauré e Hasenclever (2007) que deram origem a diversos trabalhos teóricos e empíricos sobre os elementos constitutivos dos que ficaram conhecidos como arranjos produtivos locais (APLs), sistemas locais de produção, ou simplesmente clusters ${ }^{1}$ ou aglomerações.

Os clusters podem ser definidos como aglomerações de empresas em atividades econômicas correlatas e fisicamente próximas que tendem a obter vantagens competitivas em comparação às empresas longe desse contexto. Para Porter (2000), um cluster se

\footnotetext{
${ }^{1}$ Apesar de cada linha teórica destacar características e elementos teóricos diferentes opta-se neste trabalho por utilizar de maneira geral o termo clusters por simplicidade.
} 
caracteriza pela concentração geográfica de empresas de um mesmo setor e seus agentes, tais como fornecedores e universidades. Essa proximidade física e cultural propicia externalidades associadas às interações e trocas de conhecimento mais frequentes e eficientes que aumentam a produtividade, a inovação e o potencial de crescimento, em comparação às empresas isoladas geograficamente.

Etzkowitz e Leydesdorff (2000), em seu paradigma da Hélice Tripla (Triple Helix), abordam a relação entre as empresas universidade e governo para o desenvolvimento regional. Os autores destacam que ele depende da interação frequente e articulada de empresas, universidade e governo. Dessa forma, o surgimento e a manutenção das vantagens competitivas de um cluster estão intimamente associados à interação desses agentes.

A concentração de empresas de um mesmo setor em uma região permite a aglomeração de uma cadeia produtiva comum, gerando ganhos de especialização na cadeia de fornecedores, no mercado de trabalho e nos fluxos maiores e mais intensos de informações e conhecimento. Além disso, Porter (2000) destaca que um cluster pode impulsionar a competitividade das empresas de três formas: aumentando a produtividade; ampliando a capacidade de inovação e; estimulando a formação de novos negócios (startups). Essas três influências sob a competitividade do cluster dependem muito de relações pessoais, comunicação face a face, e de redes de interações individuais e institucionais. Borges (2009) destaca também que a concentração de empresas possibilita a redução de custos e melhor integração.

Já a universidade local contribui para a formação de mão de obra qualificada e geração de novos conhecimentos e informações através da pesquisa científica. Nelson (1996) destaca a universidade como importante fonte de inovação para o setor industrial por meio da transferência de conhecimento, empreendedorismo acadêmico, desenvolvimento de bases científicas, entre outras.

Além disso, o governo tem o papel de coordenar, facilitar e prover ações que não seriam supridas de modo adequado pela o setor privado. Dessa forma, para Porter (2000) as políticas governamentais inevitavelmente afetam as oportunidades de crescimento do cluster. Portanto, o apoio governamental envolve não só o reconhecimento da existência de um cluster, mas a remoção de obstáculos, restrições e ineficiências que impedem o aumento de produtividade e a inovação no cluster, como a aplicação de diferentes políticas como subsídios e isenções. Segundo o autor, a prioridade inicial da ação pública envolve o aperfeiçoamento da infraestrutura e a eliminação de desvantagens, passando a diminuir restrições e impedimentos para a inovação nos estágios posteriores.

A dinâmica regional em que uma empresa se encontra, é um dos fatores determinantes da sua produtividade e capacidade de inovação. Segundo Suzigan et al. (2004), a aglomeração local de empresas, universidades e agentes governamentais gera interação, cooperação e aprendizado que acabam estimulando a capacidade inovativa endógena, ampliando a competitividade das empresas e conduzindo o desenvolvimento local.

Suzigan et al. (2004) destacam que os benefícios da concentração de empresas de um mesmo setor se originam de economias externas ou externalidades marshallianas e ocorrem de três maneiras: (i) pela vasta disponibilidade de fornecedores e prestadores de serviços especializados; (ii) pelo amplo contingente de trabalhadores especializados; e (iii) 
pela grande disseminação local dos conhecimentos conhecidos como transbordamentos de conhecimento que fomentam os mecanismos de aprendizado e inovação. Além disso, destacam que as empresas e demais agentes podem buscar ações conjuntas deliberadas. Esses fatores em conjunto seriam os principais determinantes da competitividade das empresas locais (SCHMITZ; NADVI, 1999).

A externalidade relacionada à presença de fornecedores especializados de matériaprima, componentes e serviços nos clusters surge porque as empresas locais demandam componentes e serviços especializados, que atraem e formam fornecedores nas imediações. Isso implica em ganhos de escala e escopo, acarretando na diminuição dos preços de seus produtos e serviços e maior variedade. Isso leva a um aumento de produtividade das empresas localizadas no cluster que levam a produtos finais com preços mais baixos e maiores margens de lucro (BRESCHI; LISSONI, 2001).

Já o amplo contingente de mão de obra especializada está associado à vasta oferta de emprego gerada pelas firmas locais. Os clusters tronam-se importantes polos de atração de trabalhadores qualificados com melhores e mais numerosas oportunidades profissionais. Além disso, como pouco do processo de formação profissional é realizado por empresas, os clusters estão habitualmente associado à presença de pelo menos uma universidade local qualificada.

Por fim, os transbordamentos tecnológicos e fluxos de conhecimentos são importantes para o desempenho do cluster já que a proximidade facilita o processo de circulação do conhecimento gerado no local. A transmissão de conhecimento ocorre através do contato interpessoal, da mobilidade de trabalhadores entre empresas e também da interação com produtores que buscam soluções condizentes com as necessidades dos clientes. E isso ocorre com maior facilidade quando há proximidade geográfica e cultural entre as empresas (BRESCHI; LISSONI, 2001).

Também é possível destacar o papel de dois elementos complementares para o desenvolvimento de um cluster e que dependem da ação conjunta dos agentes dos seus agentes: a presença de financiamento (tanto para início como expansão dos novos negócios) e a infraestrutura de governança e apoio para negócios (parques tecnológicos, incubadoras, aceleradoras, etc.).

A partir da revisão bibliográfica apresentada pode-se destacar como elementos centrais de um cluster: seus agentes constitutivos (empresas, universidade e governo), as vantagens advindas das externalidades (formação de fornecedores especializados, trabalhadores qualificados e fluxos de conhecimento), além do financiamento e estruturas de apoio. Esses elementos embasam as dimensões de análise e comparação para os clusters brasileiros deste trabalho.

\section{Setor de Tecnologia da Informação (TI) no Brasil e Clusters}

O setor de Tecnologia da Informação e Comunicação (TIC), ou simplesmente Tecnologia da Informação (TI), engloba conjuntamente os segmentos de hardware, software e serviços (DUARTE, 2012). Dentro de cada segmento, encontram-se nichos com diferente intensidade tecnológica e valor agregado, incluindo desde segmentos mais commoditizados como reparação e manutenção de equipamentos, até outros de maior valor agregado como desenvolvimento de software customizável. 
Roselino (2006) aponta que, devido à existência de barreiras, a formação e consolidação do setor de TI no Brasil teve dinâmica diferente de alguns países em desenvolvimento que se atrelaram às exportações. Pianna (2011), por sua vez, destaca que a origem das empresas nacionais do setor se focou na indústria de software sob encomenda devido à forte presença das multinacionais de hardware conformada em atividades verticais. Por isso, Costa e Garcia (2018) apontam que a maioria das empresas nacionais se consolidou atendendo mercados negligenciados pelas firmas estrangeiras, desenvolvendo atividades de menor valor agregado e específicas à demanda brasileira. Essa visão é condizente com o fato de que, segundo Roselino (2006), um elemento característico do setor é que, devido ao regime tecnológico e à sua dinâmica competitiva, coexistem empresas de diferentes tamanhos que exploram nichos de mercado com permanente mudança nos segmentos.

Do ponto de vista locacional, Diegues (2010) destaca a tendência internacional à concentração geográfica em polos, gerando clusters como o Vale do Silício, nos Estados Unidos (SAXENIAN, 1994; STURGEON, 2003), Dublin, na Irlanda, ou Bangalore, na Índia e Tel Aviv, em Israel (ARORA E GAMBARDELLA, 2005).

No Brasil, Costa e Garcia (2018) relatam que o setor encontra-se particularmente presente no Sul e Sudeste e em menor proporção no Nordeste e que grande parte dessas concentrações se dá em clusters como ilustram Britto e Stallivieri (2010) que identificam 30 microrregiões brasileiras, tanto produtivamente especializadas como diversificadas, com clusters no segmento de software e serviços.

\section{Aspectos Metodológicos}

Nesse contexto, é importante destacar que há vários trabalhos que estudam individualmente casos específicos de cluster nacionais de tecnologia analisando sua origem, estrutura, desempenho e governança. Porém, poucos trabalhos buscam fazer análises comparativas com clusters de TI como os estudos de Britto e Stallivieri (2010) e Reis e Amato Neto (2013). Já Cario e Nicolau (2012) avaliam especificamente a governança dos clusters.

A escolha dos três casos específicos merece uma menção específica. Diversos outros clusters tecnológicos nacionais poderiam ter sido destacados como: Curitiba, Florianópolis, Belo Horizonte e São José dos Campos (BRITTO; STALLIVIERI, 2010). No entanto, nesse trabalho optou-se por analisar apenas três casos (São Paulo, Campinas e Recife) que apresentam significativas diferenças estruturais no que diz respeito à cultura local e história, grau de coesão, porte e composição das empresas e papel do governo. Dessa forma, o arcabouço de análise é aproveitado para destacar similaridades e diferenças estruturais que condicionam os agentes locais e a eficácia das políticas públicas em cada cluster tecnológico analisado.

Através deste estudo, busca-se estabelecer diferenças e semelhanças que contribuíram para o sucesso dessas localidades e definir os fatores determinantes desses casos de sucesso no Brasil. A comparação se foca nas dimensões de análise previamente levantadas sobre os agentes locais (empresas, universidades e governo), além dos elementos da cadeia (fornecedores, profissionais e fluxo de ideias), além da infraestrutura de apoio e financiamento. 
O método adotado é de natureza qualitativa por meio da revisão de trabalhos prévios presentes na literatura sobre os clusters de TI nas cidades de São Paulo, Campinas e Recife. Essa análise foi complementada pelo exame de dados secundários sobre as empresas e empregados do setor (RAIS-MTE) e sobre a composição dos cursos de graduação e pósgraduação da cidade (INEP e CAPES) para os anos de 2014 e 2015. Os dados da RAIS envolveram estabelecimentos e vínculos ativos do Setor de TI. Esses dados, como apontam Suzigan et al. (2004), apresentam a vantagem de desagregação setorial e geográfica, mas tem a limitação de desconsiderar o emprego informal. Já a análise dos cursos de graduação e pós-graduação se centrou em cursos de Ciências e Engenharia da Computação mais associadas às áreas de conhecimento aplicadas no setor. Esses dados permitiram adicionar nuances as diferenças já apontadas na literatura.

Por fim, a definição do setor de TI utilizada nesse trabalho inclui hardware, software e serviços de $\mathrm{TI}$, sendo significativamente mais amplo do que alguns trabalhos que analisam isoladamente a indústria de hardware ou software.

\section{Os Casos de São Paulo, Campinas e Recife}

Esta seção apresenta busca apresentar brevemente uma visão geral dos clusters tecnológicos de TI nas cidades em estudo (São Paulo, Campinas e Recife) a partir das dimensões previamente consideradas e que fundamenta a análise comparativa.

\section{São Paulo}

Como São Paulo é a cidade mais populosa do país e concentra o principal centro financeiro, corporativo e comercial da América do Sul, com grande diversidade produtiva e social, ela pode ser classificada como uma buzz city, como postulado por Storper e Venables (2004). Segundo os autores, cidades nessas condições geram um ambiente dinâmico com amplas possibilidades de compartilhamento de conhecimento ampliando a inovação e a produtividade de profissionais e empresas. Para Costa e Garcia (2018), esse ambiente favoreceu a formação de um importante grupo de empresas de software que se beneficiam da proximidade de seus clientes e contam com ampla gama de profissionais qualificados.

Empresas locais: As empresas de TI em São Paulo possuem diferentes portes e passou por uma expansão principalmente nos anos 2000. Elas se focam em serviços intensivos em conhecimento, o que demanda mão de obra qualificada e favorece fluxos de conhecimento entre trabalhadores, pesquisadores e fornecedores. Está sediado em São Paulo um número expressivo de empresas de grande porte brasileiras (como TOTVS, Tivit e Stefanini) e multinacionais (Oracle, Google e Microsoft) o que faz com que a cidade seja sede dos líderes de mercado do setor de serviço (software customizados, consultorias, atividades de suporte, etc.).

Universidades: São Paulo possui um grande conjunto de universidades, faculdades e institutos de pesquisa e, no campo de Computação e Engenharia, há um grupo expressivo de faculdades e universidades renomadas como FATEC, FEl, Mackenzie e Mauá, mas com destaque para a Universidade de São Paulo (USP). No que diz respeito à pesquisa aplicada na área tecnológica, Zouain (2003) destaca a relevância do Instituto de Pesquisas Tecnológicas (IPT). 
Governo: Os agentes governamentais não desempenharam papel ativo na coordenação da origem do cluster tecnológico na cidade, com exceção para as fontes de financiamento estaduais e federais às startups e firmas de tecnologia (Fapesp, BNDES e FINEP) e à criação das universidades públicas. Coube, portanto, aos agentes privados coordenar e promover as ações conjuntas no período inicial. No entanto, no período recente, o governo estadual passou a desenvolver políticas de apoio à formação de startups e implantar novas estruturas como os Parques Tecnológicos.

Trabalhadores qualificados: Em decorrência da grande disponibilidade de cursos de tecnologia, a cidade possui um grande pool de profissionais qualificados formados localmente. Essa qualidade é destacada por Costa e Garcia (2018) que afirmam que a região possui profissionais com mestrado e doutorado superior à média nacional. Os autores destaca também que os fundadores de novas empresas geralmente possuíam experiência em empresas de grande porte da cidade relacionadas à área de $\mathrm{TI}$, o que aponta a formação nas empresas do cluster como papel preponderante para o reforço do contingente de profissionais qualificados.

Fornecedores especializados: Segundo Costa e Garcia (2018), a concentração de importantes firmas do setor financeiro, consultorias e serviços de engenharia na cidade, proporcionam acesso rápido às novas tecnologias e consequentemente uma rede de relacionamentos de confiança que poderá possibilitar novas oportunidades de negócios às empresas atuais ou mesmo às startups.

Fluxos de conhecimentos: A presença de um grande número de profissionais e firmas do setor na região facilita os fluxos de conhecimento formais (como treinamentos e consultoria) ou informais (interação face a face de agentes de diferentes instituições). A pesquisa de Costa e Garcia (2018) aponta relevância especial ao aprendizado devido à troca de conhecimento entre usuários e desenvolvedores nos setores de consultaria e de software sob encomenda. No entanto, o fato de empresas e universidades se encontrarem espalhadas na metrópole dificulta a criação de uma identidade e cultura local para o cluster, o que poderia facilitar interações e compartilhamento de conhecimento.

Estrutura de apoio: Além do Parque Tecnológico recentemente criado no entorno da USP, há importantes centros de apoio e incubadoras como o Cietec (Centro de Inovação, Empreendedorismo e Tecnologia), instalado no Campus da USP e que promove o empreendedorismo inovador por meio de uma incubadora de startups. Essa proximidade com a academia mostra-se relevante na formação de startups uma vez que cerca de 500 empresas haviam sido incubadas até 2014.

Investimento: Além do financiamento obtido por meio de incubadoras e aceleradoras, pode-se destacar o papel das agências públicas como a Fapesp (Fundação de Apoio a Pesquisa do Estado de São Paulo) que possui relevante orçamento anual e programas voltados especialmente ao setor tecnológico. Além disso, alguns casos a proximidade de instituições financeiras nacionais e de fundos privados facilita o acesso aos canais privados de financiamento. No entanto, eles ainda são pouco significativos em comparação com as fontes públicas.

\section{Campinas}

O cluster da região de Campinas se caracteriza como a localidade de firmas pioneiras no país com destaque das universidades e centros de pesquisas na geração de 
conhecimento e formação de pessoal. Segundo Araújo e Garcia (2010), dois agentes foram fundamentais na sua história: o CPqD (Centro de Pesquisa e Desenvolvimento), da antiga Telebrás, e a Unicamp (Universidade Estadual de Campinas).

Empresas locais: Diegues e Roselino (2009) destacam que na região de Campinas encontram-se dois grupos de empresas de TI. O primeiro inclui as firmas nacionais de software que nasceram como spinoffs da Unicamp ou do CPqD e que possuem boa interação com as instituições locais. O segundo grupo é constituído pelas multinacionais de equipamentos de telecomunicação e informática (como IBM, LG, Samsung e Ericsson). Mesmo sendo importantes geradoras de emprego e renda, elas não contribuem de forma expressiva com o fluxo de conhecimento e aprendizado do cluster.

Universidade: Todos os casos de formação de um cluster bem sucedido dependem da presença de uma universidade de alta qualidade no entorno. Em Campinas, esse papel é desempenhado pela Unicamp que se destaca na pesquisa e formação de mão de obra nas áreas de engenharia e computação. Muitos produtos são desenvolvidos em parceria com a universidade e esse vínculo dá acesso mútuo ao conhecimento e às competências que são importantes na inovação e geração de novas tecnologias no cluster. Reis e Amato Neto (2013) também apontam papel relevante dos centros de pesquisa como o CPqD e o CenPRA.

Governo: Na fase de consolidação do cluster, o governo municipal teve importante papel na estruturação de um parque tecnológico. Ganzert (2010) também credita importância ao apoio estadual e federal, inclusive pela origem da Unicamp.

Trabalhadores qualificados: Araújo e Garcia (2013) destacam que as universidades locais, centros de pesquisas e as de empresas pioneiras no setor de TI contribuíram para formação de grande contingente de profissionais qualificados. Além disso, as universidades locais possuem foco em cursos tecnológicos o que facilita a contratação de profissionais no setor de TI local.

Fornecedores especializados: Desde a instalação da IBM em 1971, o polo tecnológico de Campinas tem atraído e formado fornecedores especializados e prestadores de serviço, segundo Araújo e Garcia (2013). Além disso, as empresas que se instalam na região e as novas startups reforçam a demanda por serviços qualificados de tecnologia fundamentais para aumentar a produtividade. Esse fenômeno facilita tanto o desenvolvimento de novos produtos (mobilidade, adaptação de plataformas, engenharia de produtos) como a melhoria das estruturas internas (armazenamento de dados, segurança, treinamento, consultoria) que ampliam a competitividade de empresas nos arredores de Campinas.

Fluxos de conhecimento: Roselino (2006), Ganzert (2010) e Araújo e Garcia (2013) destacam que as relações entre empresas se restringe às empresas locais vinculadas à Unicamp e ao CPqD. Araújo e Garcia (2013) destacam ainda que grande parte do conhecimento flui de maneira local e informal entre as empresas e universidades locais. Por outro lado, indicam que o fluxo de informações entre multinacionais e empresas nacionais é limitado.

Estrutura de apoio: No que diz respeito à infraestrutura, a região de Campinas está dotada de instituições de apoio à criação de startups, processo de incubação e aceleração de empresas. Destaque especial pode ser dado à agência de Inovação da Unicamp (Inova) que promove uma incubadora de empresas (Incamp) e a CIATEC (Companhia de Desenvolvimento do Polo de Alta Tecnologia de Campinas). 
Investimentos: Dada a pouca disponibilidade de venture capital, em 2011 foi fundada a Inova Venture Participações (IVP) para investir em empresas de tecnologia, permitindoas crescer até se tornarem mais atrativas para aporte de empresas de venture capital. Além disso, como nos outros casos, as agências públicas como Fapesp, FINEP e BNDES se destacam no apoio financeiro às empresas do polo.

\section{Recife}

O Porto Digital, em Recife, é um cluster tecnológico que originou e atraiu diversas empresas, inclusive multinacionais, e tem se destacado pelo rápido crescimento, dinamismo e forte cultura local. Para Araújo (2006), o Porto Digital se apresenta como importante fruto de um conjunto de políticas públicas, uma vez que o projeto envolveu importante apoio governamental e um plano urbanístico de revitalização do Porto Antigo do Recife, e pelo bom aproveitamento de externalidades de uma instituição de ensino e pesquisa renomada como a Universidade Federal de Pernambuco (UFPE).

Empresas locais: O Porto Digital é voltado especialmente para software e serviços e abriga cerca de 250 empresas, incluindo multinacionais como Accenture e IBM. No entanto, Britto e Stallivieri (2010) indicam que no Recife predominam empresas de porte pequeno e médio. Entre as iniciativas sediadas no cluster, destaca-se o C.E.S.A.R. (Centro de Estudos e Sistemas Avançados do Recife), que foi criado por professores e pesquisadores da UFPE. Araújo (2006) aponta-o como agente articulador central, muito relacionado a um grande número de startups que dá origem comum e reforça o relacionamento entre empresas que gera sinergias em produtos e serviços.

Universidades: Entre as universidades locais, há especial destaque para a UFPE que está intimamente associada à origem do cluster. Os seus centros de Informática e Engenharia se destacam pela relevante publicação internacional e como seus professores e pesquisadores deram origem ao C.E.S.A.R. e depois ao Porto Digital há um forte vínculo com as empresas locais. Isso faz com que o conhecimento gerado na universidade seja aplicado nas empresas gerando novas fontes de pesquisa. Além disso, grande parte da mão de obra local se formou nos cursos de graduação e pós-graduação em Ciência e Engenharia da Computação dessa universidade.

Governo: O Porto Digital teve início não só como um polo de empresas, mas foi associado desde suas origens a um plano governamental de desenvolvimento territorial e urbanístico o qual teve importante papel no investimento deste projeto. Araújo (2006) destaca que os governos municipal e estadual atuaram abrindo linhas de financiamento, fundos, programas de incentivos fiscais, além de atuar na governança do cluster visando aumentar a competitividade das empresas e atrair negócios inovadores. Além disso, incentivos Federais como a Lei da Informática geraram importantes benefícios locais.

Trabalhadores qualificados: O surgimento do Porto Digital levou em conta o grande número de formandos dos cursos ligados à computação da UFPE que muitas vezes seguiam carreira fora da cidade. Antes do surgimento dessa iniciativa, Araújo (2006) aponta que cerca de $75 \%$ desses graduados saiam do Recife. De fato, o sucesso do cluster dependeu em boa medida do aproveitamento desses profissionais e teve como consequência não só reduzir à saída de mão de obra especializada, como levou ao fenômeno oposto, transformando Recife num centro de atração de profissionais de outras 
localidades. No que diz respeito à qualificação, Costa e Garcia (2018) apontam que Recife se destaca como o maior contingente proporcional de trabalhadores no ramo de desenvolvimento de serviços customizáveis que atuam nas empresas de alta tecnologia de nichos especializados.

Fornecedores especializados: Ainda que as primeiras empresas de TI tenham se instalado em Recife nos anos de 1970, a região nunca desenvolveu número expressivo de fornecedores especializados, seja de infraestrutura ou serviços. Apenas com o impulso dado pela formação do Porto Digital é que surgiram os primeiros fornecedores locais para atender a demanda das firmas que lá surgiram ou se instalaram. Nesse sentido, o cluster desenvolveu um conjunto de fornecedores especializados.

Fluxos de conhecimento: O vínculo existente entre a universidade local e as empresas do Porto Digital pode ser evidenciado porque grande parte dos empreendedores e funcionários do cluster formou-se na UFPE ou atuou em alguma etapa profissional no C.E.S.A.R. Esse fato gera maior coesão e reforça a cultura local gerando uma maior propensão à colaboração. Além disso, a proximidade do mundo acadêmico facilita a pesquisa e projetos conjuntos com empresas ou startups gerando inclusive publicações acadêmicas.

Estrutura de apoio: O Porto Digital dispõe de duas incubadoras e aceleradoras (Jump Brasil e C.E.S.A.R. Labs) que visam alavancar novos negócios e melhorar o desempenho de startups oferecendo infraestrutura, apoio estratégico e investimento.

Investimentos: No quesito venture capital, o cenário no Porto Digital tem apresentado melhoras, atraindo investidores privados, como a participação acionaria obtida pelas startups por meio das incubadoras. No entanto, o grande financiador continua sendo o governo, com destaque para o fundo Criatec (ligado ao BNDES), FINEP e inclusive CNPq. Além disso, são importantes os incentivos fiscais, que além da esfera federal se apoiam em instrumentos municipais e estaduais.

\section{Análise Comparativa dos Clusters Selecionados}

Nesta seção, as características e os fatores dos clusters selecionados são analisados em conjunto formando um comparativo entre as regiões de São Paulo, Campinas e Recife. Como na seção anterior, a comparação é feita pelas dimensões de análise propostas e com dados secundários. Além disso, os achados são sumarizados em um quadro.

Empresas locais: Os três clusters possuem particularidades no que diz respeito ao porte e segmento de atuação das empresas. No que tange o segmento de atuação, pelo número de empregados e estabelecimentos da RAIS de 2015 (cf. Tabela 1), é possível verificar que o segmento de hardware é pouco expressivo no Recife (4,5\% das empresas e $3,9 \%$ do emprego) o que evidencia a sua concentração em software e serviços como aponta Britto e Stallivieri (2010). Já em São Paulo, hardware possui alguma importância, mas é em Campinas que este segmento se destaca respondendo por $17,8 \%$ das empresas e $37,0 \%$ do emprego, refletindo também a importância relativa da indústria nessas cidades.

Já no que diz respeito ao porte, as empresas médias e pequenas são as mais numerosas e responsáveis por grande parte do emprego local como esperado para todo o setor de TI. Nos clusters de São Paulo e Recife, pequenas e médias empresas respondem por mais de $83,1 \%$ e $77,3 \%$ do total de trabalhadores, respectivamente. Já em Campinas, as 
empresas grandes tem grande importância na geração de emprego, uma vez que empresas com mais de 1.000 empregadores respondem por 50,5\% das vagas do setor de Tl.

São Paulo e Campinas sediam grandes empresas nacionais e de multinacionai, porém, em São Paulo elas se concentram em software e serviços (Google, IBM, HP, Facebook, p.ex.), enquanto em Campinas elas também atuam em hardware (Dell, p.ex.) e equipamentos para telecomunicações (Ericsson, p.ex.). Tendo em conta que a montagem de hardware demanda especial volume de mão de obra, compreende-se que a relevância das multinacionais de hardware em Campinas se reflita no maior emprego de empresas grandes.

Em todos os casos, há forte presença de várias pequenas e médias empresas de alta tecnologia voltadas para nichos especializados e muitas vezes startups de origem acadêmica ou de empresas locais consolidadas.

Tabela 1. Empregados e Empresas por Segmento e Porte

\begin{tabular}{|c|c|c|c|c|c|}
\hline & Região Metropolitana & $\begin{array}{l}\text { Hardware e } \\
\text { Eletrônico }\end{array}$ & Software & Serviços de TI & $\begin{array}{c}\text { Total } \\
\text { Setor TI }\end{array}$ \\
\hline \multirow{3}{*}{$\begin{array}{c}\text { N. Empresas } \\
(\%)\end{array}$} & São Paulo & $948(12,7 \%)$ & $4.422(59,0 \%)$ & $2123(28,3 \%)$ & 7.493 \\
\hline & Campinas & $144(17,8 \%)$ & $451(55,7 \%)$ & $214(26,5 \%)$ & 809 \\
\hline & Recife & $27(4,5 \%)$ & $399(67,1 \%)$ & $169(28,4 \%)$ & 595 \\
\hline \multirow{4}{*}{$\begin{array}{c}\mathrm{N} . \\
\text { Empregados } \\
(\%)\end{array}$} & São Paulo & $23.930(13,0 \%)$ & $128.763(69,7 \%)$ & $32.014(17,3 \%)$ & 184.707 \\
\hline & Campinas & $11.511(37,0 \%)$ & $17.989(57,8 \%)$ & $1.607(5,2 \%)$ & 31.107 \\
\hline & Recife & $423(3,9 \%)$ & $6.341(58,4 \%)$ & $4.087(37,7 \%)$ & 10.851 \\
\hline & & $\begin{array}{c}\text { Micro } \\
\text { (5 a } 9 \text { Empr) }\end{array}$ & $\begin{array}{l}\text { Pequena } \\
(50 \text { a 99) }\end{array}$ & $\begin{array}{c}\text { Média } \\
(500 \text { a 999) }\end{array}$ & $\begin{array}{l}\text { Grande } \\
(\geq 1000)\end{array}$ \\
\hline \multirow{4}{*}{$\begin{array}{c}\text { N. Empresas } \\
(\%)\end{array}$} & São Paulo & $3.580(66,7 \%)$ & $1.515(28,2 \%)$ & $260(4,8 \%)$ & $15(0,3 \%)$ \\
\hline & Campinas & $401(67,4 \%)$ & $164(27,6 \%)$ & $25(4,2 \%)$ & $5(0,8 \%)$ \\
\hline & Recife & $459(77,1 \%)$ & $120(20,2 \%)$ & $15(2,5 \%)$ & $1(0,2 \%)$ \\
\hline & São Paulo & $14.954(8,1 \%)$ & $54874(29,7 \%)$ & $83.734(45,4 \%)$ & $31.145(16,9 \%)$ \\
\hline \multirow{2}{*}{$\begin{array}{c}\mathrm{N} . \\
\text { Empregados } \\
(\%)\end{array}$} & Campinas & $1.642(5,3 \%)$ & $5.296(17,0 \%)$ & $8.462(27,2 \%)$ & $15.707(50,5 \%)$ \\
\hline & Recife & $1.382(12,7 \%)$ & $3.250(30,0 \%)$ & $3.644(33,6 \%)$ & $2.461(22,7 \%)$ \\
\hline
\end{tabular}

Fonte: RAIS-MTE (2015)

Divisões CNAE 2.0 adotadas: Hardware e Eletrônicos: 26. Fabricação de Equip. de Informática, Prod. Eletrônicos e Opticos; Software: 62. Atividades dos Serviços de Tecnologia da Informação; Serviços de TI: 63. Atividades de Prestação de Serviços de Informação.

Universidades: A ampla oferta de cursos voltados à área de $\mathrm{Tl}$ e a presença de universidades de excelência foi fundamental para o surgimento e consolidação dos polos de tecnologia analisados.

Os dados de matrículas do Censo do INEP de 2014 nas áreas de Engenharias, Computação e Afins estão consolidados na Tabela 2. As três cidades possuem contingente expressivo de formandos nessas áreas com mais de 20 mil matriculados em Recife e Campinas e mais de 120 mil em São Paulo. Além disso, nos três casos, há maior proporção de matrículas nesses cursos do que a média nacional. Também fica bastante evidente o maior foco de Campinas em cursos tecnológicos, pois esses cursos correspondem a 34,0\% das matrículas na cidade frente $20,8 \%$ de média nacional. 
Tabela 2. Matrículas por Área do Conhecimento em 2014.

\begin{tabular}{crrr} 
Cidade & $\begin{array}{c}\text { Engenharia, } \\
\text { Computação e } \\
\text { Afins }\end{array}$ & $\begin{array}{c}\text { Engenharia, } \\
\text { Comp. e Afins } \\
\text { (\%) }\end{array}$ & Matrículas Totais \\
\hline São Paulo & 128.529 & $23,0 \%$ & 559.224 \\
Campinas & 24.611 & $34,0 \%$ & 72.489 \\
Recife & 28.983 & $26,0 \%$ & 111.379 \\
\hline Total Brasil & 1.406 .962 & $20,8 \%$ & 6.776 .049 \\
\hline Tonte: INEP $(2014)$ & & &
\end{tabular}

Já no que diz respeito à Pesquisa Acadêmica, os cursos de pós-graduação em Ciências e Engenharia da Computação das universidades de referência locais (USP, Unicamp e UFPE) são fundamentais os pós-graduados e pesquisadores tendem a prolongar o vínculo com a pesquisa acadêmica, permitindo o desenvolvimento e estudo aplicado para soluções das empresas locais.

Por meio dos dados da CAPES de 2015 na Tabela 3, é possível verificar o número de professores doutores vinculados a programas de pós-graduação nas áreas de Ciências da Computação e Engenharia Elétrica. Se São Paulo tem cerca de 5 vezes mais graduandos que Recife e Campinas, o número de docentes nas áreas de TI não é tão díspar. São 149 docentes em Campinas, 233 em Recife e 353 em São Paulo. Essa ordem de grandeza semelhante reflete a importância das universidades públicas como principais responsáveis pelos programas de pós-graduação e pesquisa acadêmica. Do ponto de vista relativo, há maior importância para Recife e Campinas que possuem 7,6\% e 5,7\% docentes atuando nessas duas áreas, contra 3,2\% em São Paulo. Esses dados evidenciam o maior peso dessas áreas de pesquisas na UFPE e Unicamp.

Tabela 3. Prof. Dr. em Programas de Pós Graduação

\begin{tabular}{|c|c|c|c|}
\hline Região Metropolitana & $\begin{array}{l}\text { Prof. Dr. Pós em C.Comp. } \\
\text { e Eng. Elétrica }\end{array}$ & $\%$ Total & $\begin{array}{l}\text { Total } \\
\text { Geral }\end{array}$ \\
\hline Campinas & 149 & $5,7 \%$ & 2.609 \\
\hline Recife & 233 & $7,6 \%$ & 3.077 \\
\hline São Paulo & 353 & $3,2 \%$ & 11.043 \\
\hline
\end{tabular}

Além disso, é importante recordar que o papel de universidade e centros de pesquisa das três cidades como polos de colaboração com empresas e origem de importantes spinoffs e destacar, no caso de Recife, o papel da UFPE como articuladora da formação do Porto Digital e do C.E.S.A.R.

Governo: Em Recife, os órgãos municipais e estaduais estiveram desde o início na origem e estruturação do Porto Digital com incentivos fiscais, planejamento de curto e longo prazo, apoio institucional e um projeto de revitalização urbanística. Ainda hoje, o apoio governamental é fundamental para seu desenvolvimento e expansão, uma vez que órgãos governamentais participam ativamente da governança do cluster. Em Campinas, o governo municipal também foi importante para constituir o parque tecnológico local e, na 
cidade de São Paulo, o papel do governo local só se tornou mais expressivo no período recente. Já no âmbito do estado de São Paulo, deve-se destacar o papel da Fapesp como importante financiadora de empresas de base tecnológica e de projetos com a acadêmica, além da ação dos projetos para constituir os Parques Tecnológicos Paulistas. Por fim, é necessário recordar a atuação indireta do Estado por meio das universidades de referência nos três clusters estudados que são públicas e foram fundamentais articuladores das estruturas de apoio.

Trabalhadores qualificados: Além dos centros de excelência de ensino que proporcionam a formação de mão de obra de alta qualificação, as três regiões estudadas possuem um grande conjunto de universidades de cursos de tecnologia. A região metropolitana de São Paulo se destaca pelo grande número de cursos renomados (FATEC, FEl, Mauá, Mackenzie) que formam novos profissionais todos os anos, como visto anteriormente pelo número de matriculados. Já a região de Campinas conta com menos centros de ensino relevantes, mas há especial foco nos cursos de tecnologia. Em Recife, a oferta é um pouco menor, mas é especialmente relevante e de qualidade no nível de pósgraduação, especialmente na UFPE. As três cidades acabam servido também como polo de atração de profissionais qualificados de outras localidades, porém, em Recife, esse influxo migratório é mais recente que em São Paulo e Campinas.

Fornecedores especializados: Campinas e São Paulo apresentam um conjunto bem estruturado de empresas fornecedoras de serviços e infraestrutura especializada para $\mathrm{TI}$ como serviços de rede, segurança ou armazenamento e consultorias. Recife, por sua vez, vem desenvolvendo essa rede de fornecedores no período recente, especialmente após a demanda de empresas do próprio Porto Digital.

Fluxos de conhecimentos: As três regiões possuem fluxos de conhecimento expressivos entre os agentes locais, mas com características distintas. Na região metropolitana de São Paulo, a grande diversidade e dinamismo das interações pessoais permite que conhecimentos mais complexos fluam com facilidade entre agentes, no entanto, a falta de uma cultura local forte implica em menor coesão desses agentes. Já na região de Campinas, os fluxos de conhecimentos são valiosos, pois a Unicamp e o CPqD geram importantes vínculos entre as empresas nacionais, facilitando o fluxo de conhecimento e inovação no setor. Porém, as empresas multinacionais não participam destes fluxos de conhecimento. Por fim, no Recife a cultura local é muito forte, o que proporciona coesão e cooperação entre todos os agentes inseridos no Porto Digital favorecendo amplamente o fluxo de conhecimentos entre empresas, universidades e governo.

Estrutura de apoio: Apesar dos diferentes graus de maturidade trajetórias, os três casos analisados apresentam relevante rede de apoio com incubadoras, aceleradoras e Parques Tecnológicos estabelecidos com diferentes graus de integração e coesão no cluster.

Investimento: No que diz respeito ao financiamento, Ribeiro (2005) aponta que os agentes privados possuem ainda um papel secundário, sendo prevalente o financiamento por órgãos públicos. Por isso, grande parte do financiamento do setor de TI dessas localidades é obtida por agências públicas (FINEP, BNDES e Fapesp). Por isso, os clusters estudados refletem a deficiência de fontes privadas de investimento em venture capital que é suprido parcialmente por canais intermediados por aceleradoras e incubadoras que 
fornecem uma das poucas fontes privadas de financiamento às startups. Porém, em São Paulo, pode-se dizer que esse problema é mitigado pela proximidade de um maior número de investidores e do mercado financeiro nacional.

A seguir, é apresentado um quadro comparativo que sintetiza os principais resultados e a comparação dos clusters estudados.

Quadro 1. Síntese dos Resultados da Análise Comparativa

\begin{tabular}{|c|c|c|c|c|}
\hline $\begin{array}{l}\text { Dimensão de } \\
\text { Análise }\end{array}$ & Comentários Gerais & São Paulo & Campinas & Recife \\
\hline Empresas & $\begin{array}{l}\text { Firmas pequenas e } \\
\text { médias de software } \\
\text { predominam grandes. }\end{array}$ & $\begin{array}{c}\text { Principais líderes nacionais e } \\
\text { internacionais. Mais voltadas } \\
\text { para software e serviços }\end{array}$ & $\begin{array}{c}\text { Grandes empresas } \\
\text { multinacionais. Maior } \\
\text { presença de empresas de } \\
\text { hardware e } \\
\text { telecomunicações }\end{array}$ & $\begin{array}{l}\text { Menos empresas } \\
\text { grandes. Maior } \\
\text { importância de } \\
\text { pequenas e médias. }\end{array}$ \\
\hline Universidades & $\begin{array}{c}\text { Boas universidades. } \\
\text { Grande número de } \\
\text { profissionais com pós- } \\
\text { graduação. Vínculos com } \\
\text { academia. }\end{array}$ & $\begin{array}{l}\text { Grande número de } \\
\text { universidades e de } \\
\text { profissionais formados. } \\
\text { Centro de Excelência: USP }\end{array}$ & $\begin{array}{l}\text { Cursos maios voltados para } \\
\text { a área tecnológica. Centro } \\
\text { de Excelência: Unicamp. }\end{array}$ & $\begin{array}{l}\text { Cursos de pós- } \\
\text { graduação mais focados } \\
\text { em TI. Centro de } \\
\text { Excelência: UFPE. }\end{array}$ \\
\hline Governo & $\begin{array}{l}\text { Papel na formação e } \\
\text { apoio dos polos. }\end{array}$ & $\begin{array}{l}\text { Expressivo nas estruturas } \\
\text { de apoio e financiamento. }\end{array}$ & $\begin{array}{l}\text { Expressivo apoio para a } \\
\text { formação do polo, mas } \\
\text { ainda pouco atuante. }\end{array}$ & $\begin{array}{l}\text { Grande apoio do } \\
\text { governo local com } \\
\text { incentivos e plano } \\
\text { urbanístico. }\end{array}$ \\
\hline $\begin{array}{c}\text { Trabalhadores } \\
\text { qualificados }\end{array}$ & $\begin{array}{c}\text { Abundante e qualificada } \\
\text { nas três. }\end{array}$ & $\begin{array}{c}\text { Grande volume de cursos. } \\
\text { Alta atratividade para } \\
\text { profissionais de outras } \\
\text { regiões. }\end{array}$ & $\begin{array}{c}\text { Importantes cursos } \\
\text { tecnológicos. Universidades } \\
\text { mais focadas em TI. Atração } \\
\text { de outros locais }\end{array}$ & $\begin{array}{l}\text { Importantes cursos } \\
\text { tecnológicos, mas em } \\
\text { menor número de } \\
\text { cursos. Recente atração } \\
\text { de outros locais. }\end{array}$ \\
\hline $\begin{array}{l}\text { Fornecedores } \\
\text { especializados }\end{array}$ & $\begin{array}{c}\text { Todas com fornecedores, } \\
\text { mas diferem em } \\
\text { tamanho. }\end{array}$ & $\begin{array}{c}\text { Cidade global, acesso rápido } \\
\text { a novas tecnologias. Amplo } \\
\text { número de fornecedores. }\end{array}$ & $\begin{array}{c}\text { Fornecedores já antigos e } \\
\text { estabelecidos. }\end{array}$ & $\begin{array}{l}\text { Menos fornecedores. } \\
\text { Formados com o cluster. }\end{array}$ \\
\hline $\begin{array}{c}\text { Fluxos de } \\
\text { conhecimento }\end{array}$ & $\begin{array}{l}\text { Fluxos de conhecimento } \\
\text { existentes, mas distintos. }\end{array}$ & $\begin{array}{c}\text { Grande diversidade gera } \\
\text { contatos ricos (buzz city), } \\
\text { mas menor coesão. }\end{array}$ & \begin{tabular}{|c|} 
Importantes fluxos \\
intermediados pela Unicamp \\
e CNPq. Multinacionais \\
isoladas.
\end{tabular} & $\begin{array}{l}\text { Cultura local forte gera } \\
\text { coesão. Grande } \\
\text { incentivo ao } \\
\text { empreendedorismo. }\end{array}$ \\
\hline $\begin{array}{l}\text { Estrutura de } \\
\text { apoio }\end{array}$ & $\begin{array}{l}\text { Estrutura presente e } \\
\text { similar. }\end{array}$ & $\begin{array}{c}\text { Parque Tecnológico. } \\
\text { Incubadoras e aceleradoras. }\end{array}$ & $\begin{array}{c}\text { Parque Tecnológico. } \\
\text { Incubadoras e aceleradoras. }\end{array}$ & $\begin{array}{l}\text { Parque Tecnológico. } \\
\text { Incubadoras e } \\
\text { aceleradoras. }\end{array}$ \\
\hline Investimento & $\begin{array}{l}\text { Concentrado em fundos } \\
\text { governamentais. Pouco } \\
\text { acesso a fundos privados } \\
\text { por meio de incubadoras } \\
\text { e aceleradoras. }\end{array}$ & $\begin{array}{c}\text { Fapesp muito importante } \\
\text { para startups com vínculo } \\
\text { acadêmico e órgãos federais } \\
\text { (BNDES e FINEP). }\end{array}$ & $\begin{array}{c}\text { Fapesp muito importante } \\
\text { para startups com vínculo } \\
\text { acadêmico e órgãos federais } \\
\text { (BNDES e FINEP). }\end{array}$ & $\begin{array}{c}\text { Concentração em } \\
\text { órgãos federais (BNDES } \\
\text { e FINEP). }\end{array}$ \\
\hline
\end{tabular}

Fonte: elaborado pelos autores.

\section{Considerações Finais}

Este trabalho buscou estabelecer uma análise comparativa entre os clusters ou polos tecnológicos de São Paulo, Campinas e Recife, avaliando pontos positivos e negativos de cada região. Essa comparação se deteve em elementos estruturais como a composição dos agentes de cada cluster (empresas, universidades e governo), as vantagens locacionais (mão de obra qualificada, fornecedores especializados e fluxos de conhecimento), além do papel da infraestrutura de apoio e financiamento. 
A comparação permite apontar várias similaridades entres os casos estudados e algumas singularidades. Entre os pontos comuns, nota-se que todos os três clusters se concentram mais em atividades de software e serviços e há grande importância de pequenas e médias empresas na geração de emprego. Todas as regiões possuem uma estrutura universitária voltada para o setor tecnológico e vínculos com universidades de ponta. Além disso, existem importantes fluxos de conhecimento locais ainda que ocorram de forma e intensidade distintas. Por fim, todos os casos possuem estruturas bem estabelecidas de apoio, mas com dependência das fontes públicas de financiamento.

No campo das singularidades, é possível destacar em Campinas a maior relevância das grandes empresas e do setor de hardware. No Recife, destaca-se a forte coesão dos agentes e uma maior presença de agentes governamentais não somente como apoio, mas também que na governança do Porto Digital. Por fim, em São Paulo verifica-se um pouco menos a restrição ao financiamento privado e grande vantagem de fluxos de aprendizado por interação com clientes.

Trabalhos como o presente estudo possuem relevância não só para a compreensão de pontos positivos e negativos dos casos de sucesso, mas também para a formulação de políticas públicas para a promoção e desenvolvimento de clusters e para o setor de TI. Isso se dá porque uma análise comparativa auxilia a distinguir melhor de problemas ou deficiências específicas aos clusters particulares dos elementos estruturais de todo o setor de TI nacional. No primeiro caso, serviram para pautar medidas pontuais ou particulares para cada cluster. No segundo, serviriam como apoio para a agenda de Políticas Industrial, Tecnológica e Científica relacionada o setor de TI no Brasil. Para isso, seria necessário desenvolver mais estudos comparativos com outros casos de relevância nacional.

\section{REFERÊNCIAS}

ARAÚJO, V. Surgimento e crescimento do Porto Digital: o papel das políticas públicas e da universidade. Anais do IX Simpósio de Administração da Produção, Logística e Operações Internacionais. SIMPOI. FGV-EAESP, São Paulo, 2006.

ARAÚJO, V.; GARCIA, R. Transbordamentos locais de conhecimento por meio de contatos informais: uma análise a partir do sistema local de indústrias TIC de Campinas. Revista Brasileira de Inovação, v. 12, n. 1 jan/jun, p. 105-132, 2013.

ARORA, A.; GAMBARDELLA, A. The globalization of the software industry: perspectives and opportunities for developed and developing countries. Innovation policy and the economy, v. 5, p. 1-32, 2005.

BORGES, M. A. G. A tríplice hélice e o desenvolvimento do setor de tecnologia da informação no Distrito Federal. Tese de Doutorado. Universidade de Brasília, Brasília, 2009 .

BRESCHI, S.; LISSONI, F. Knowledge spillovers and local innovation systems: a critical survey. Industrial and corporate change, v. 10, n. 4, p. 975-1005, 2001. 
BRITTO, J.; STALLIVIERI, F.. Inovação, cooperação e aprendizado no setor de software no Brasil: análise exploratória baseada no conceito de Arranjos Produtivos Locais (APLs).

Economia e Sociedade, v. 19, n. 2, p. 315-358, 2010.

CARIO, S. A. F.; NICOLAU, J. A. Estrutura e padrão de governança em arranjos produtivos locais no Brasil: um estudo empírico. Ensaios FEE, v. 33, n. 1, p. 177-206, 2012.

CASSIOLATO, J. E.; LASTRES, H. M. M. Arranjos e sistemas produtivos locais na indústria brasileira. Revista de economia contemporânea, v. 5, p. 103-136, 2001.

COSTA, A. R.; GARCIA, R. Aglomeração Produtiva e Diversificação: Um Enfoque Sobre os Serviços de Tecnologia da Informação. Revista Brasileira de Estudos Urbanos e Regionais, Vol. 20, n. 2. P. 325-341. 2018.

DIEGUES, A. C. Atividades de software no Brasil: Dinâmica concorrencial, política industrial e desenvolvimento. Tese de Doutorado. Universidade Estadual de Campinas, Campinas, 2010.

DIEGUES, A. C.; ROSELINO, J. E. Interação, Aprendizado Tecnológico e Inovativo no Pólo de TIC da Região de Campinas: uma caracterização com ênfase nas atividades tecnológicas desenvolvidas pelas empresas beneficiárias da Lei de Informática. Revista Brasileira de Inovação, v. 5, n. 2 jul/dez, p. 373-402, 2009.

DUARTE, V. Caracterização da IBSS. In: SOFTEX. Software e Serviços de TI: A indústria brasileira em perspectiva. Observatório SOFTEX, vol. 2, Campinas. 2012.

ETZKOWITZ, H; LEYDESDORFF, L. The dynamics of innovation: from National Systems and "Mode 2" to a Triple Helix of university-industry-government relations. Research Policy, v. 29, n. 2, p. 109-123, 2000.

FAURÉ, Y. A.; HASENCLEVER, L. Caleidoscópio do desenvolvimento local no Brasil: diversidade das abordagens e das experiências. Editora E-papers, 2007.

GANZERT, Christian Carvalho. Desenvolvimento sistêmico de polos regionais de tecnologia da informação: Análise comparativa entre modelos de clusters nacionais e internacionais sob a perspectiva da teoria dos sistemas. Dissertação de Mestrado. Universidade de São Paulo, Ribeirão Preto, 2010.

NELSON, R. R. The sources of economic growth. Cambridge, MA: Harvard University Press, 1996.

PIANNA, A. Padrões de especialização, inserção internacional e dinamismo na indústria de software: o caso brasileiro à luz das experiências da Índia, Irlanda e Israel. Dissertação de Mestrado. Universidade de São Paulo, São Paulo, 2011. 
PORTER, M. E. Location, Competition, and Economic Development: Local Clusters in a Global Economy. Economic Development Quartely,, Vol.14 No. 1, Feb., p. 15-34, 2000

REIS, A. P.; AMATO NETO, J.. Aprendizagem por cooperação em rede: práticas de conhecimento em arranjos produtivos locais de software. Production, v. 22, n. 3, p. 345355, 2012.

RIBEIRO, L. de L. O modelo brasileiro de private equity e venture capital. 2005. $137 \mathrm{f}$. Dissertação de Mestrado. Universidade de São Paulo, São Paulo, 2005.

ROSELINO, J. E.. A Indústria de Software: o “modelo brasileiro" em perspectiva comparada. Tese de Doutorado. Universidade de Campinas, Campinas, 2006.

SAXENIAN, A.. Regional Advantage: Culture and Competition in Silicon Valley and Route 128. Harvard University Press, 1996.

SCHMITZ, H.; NADVI, K. Industrial Clusters In Developing Countries-Clustering and Industrialization: Introduction. World Development, v. 27, n. 9, p. 1503-1514, 1999.

STORPER, M.; VENABLES, A. J. Buzz: face-to-face contact and the urban economy. Journal of Economic Geography, v. 4, n. 4, p. 351-370, 2004.

STURGEON, T. J. What really goes on in Silicon Valley? Spatial clustering and dispersal in modular production networks. Journal of Economic Geography, v. 3, n. 2, p. 199-225, 2003.

SUZIGAN, W. Aglomerações industriais como focos de políticas. Revista de Economia Política, v. 21, n. 3, p. 83, 2001.

SUZIGAN, W., et al. Clusters ou sistemas locais de produção: mapeamento, tipologia e sugestões de políticas. Revista de Economia Política, Vol. 24, n. 4, p. 543-562, 2004. ZOUAIN, D. M.. Parques tecnológicos propondo um modelo conceitual para regiões urbanas. O parque tecnológico de São Paulo. Tese de Doutorado. Universidade de São Paulo. São Paulo, 2003.

Veneziano Araujo. Universidade Federal de São Paulo.veneziano.araujo@unifesp.br Ana Laura Costa Lopes. Universidade Federal de São Paulo. ana.laura1811@hotmail.com 
Análise Comparativa dos Clusters de Empresas de Tecnologia da Informação de São Paulo, Campinas e Recife

Como citar: ARAUJO, Veneziano de Castro; COSTA LOPES, Ana Laura. Análise Comparativa dos Clusters de Empresas de Tecnologia da Informação de São Paulo, Campinas e Recife. Redes, Santa Cruz do Sul, v. 24, n. 2, p. 233-251, maio 2019. ISSN 1982-6745. Disponível em: https://doi.org/10.17058/redes.v24i2.11163. 